\title{
Research Paper: Study of Face and Content Validity of the Persian Version of Behavior Rating Inventory of Executive Function, Preschool Version
}

\author{
Foroozan Abdollahipour ${ }^{1}$, ${ }^{*}$ Mehdi Alizadeh Zarei ${ }^{1}$, Malahat Akbar Fahimi ${ }^{1}$, Samaneh Karamali Esmaeili ${ }^{1}$
}

1. Department of Occupational Therapy, Faculty of Rehabilitation, Iran University of Medical Sciences, Tehran, Iran.

Citation: Abdollahipour F, Alizadeh Zarei M, Akbar Fahimi M, Karamali Esmaeili S. [Study of face and content validity of the Persian version of behavior rating inventory of executive function, preschool version (Persian)]. Journal of Rehabilitation. 2016; 17(1):12-19. http://dx.doi.org/10.20286/jrehab-170110

http://dx.doi.org/10.20286/jrehab-170110

Received: 3 Jul. 2015 Accepted: 11 Jan. 2016
Keywords:

Children, Executive function, Preschool, Validity

\begin{abstract}
A B STRACT
Objective Executive functions are referred to higher and self-tuning cognitive processes that help managing behaviors and thought controls. Executive functions in children are assessed in different ways. The most prestigious and valuable way is using daily functions reports on a child's natural environment. This study aimed to prepare the Persian version of behavior rating inventory of executive function-preschool (BRIFF-P) and study of its face and content validity among Iranian children. The questionnaire completed by parents of 2-5 years old children.

Materials \& Methods This study has methodological and psychometric design. We studied the Persian version of tests using standard protocols IQOLA and determined its validity. This protocol includes translation, evaluation of translation quality, backward translation, and comparing the English version with its Persian one. Face validity was determined by 20 samples (parent) and the impact score was measured. Content validity index (CVI) and ratio of the content validity (CVR) was determined by asking the opinions of 15 experts. Moreover, the simplicity, relevance, and transparency of each item was evaluated.

Results Based on the simplicity and clarity of questionnaire items, over $80 \%$ agreement of the sample group indicated the simplicity and clarity of the items. also the difficult and complex items were discussed among experts in several sessions and as a result the simpler and clearer concepts took the place of difficult and ambiguous items. Then, the score of proportion index effect and relation of items for each of 63 items of questionnaire was calculated. the results showed that all items of questionnaire were simple and clear, also all items except 7 achieved impact score of higher than 1.5. To evaluate the content validity of the questionnaire, we used ratio of content validity and index calculation. Content validity showed that almost all items of the questionnaire achieved CVI score of higher than 0.79 (The lowest score was 0.8 and highest one was 1); however, as regards the index of relatedness, 3 items got scores lower than 0.79 The scores of the content validity ratio were more than 0.49 , except the fifth item.

Conclusion The Persian version of this questionnaire possesses a good match in terms of cultural and face validity. The results of content validity confirms that the Persian version is clear, simple, and understandable for the target society. However, 7 items of the questionnaire got scores lower than 1.5. of course, as in this study, the parents of normal children were investigated, the importance of these items in evaluation of abnormal children must be considered, because in many abnormal growth development of children (like attention deficit/hyperactivity, autism) such behaviors are clearly considered problematic. Therefore, the importance of these items are seen in final questionnaire and in spite of low score of 1.5 of some items, in the sample group (normal children), these items were kept and inserted in the final questionnaire. The results of content validity were also indicative of different cultural assumptions from some items of this questionnaire. We suggest that in future studies, the content validity of the Persian version was estimted with regard to opinions of parents of abnormal children with growth development problems and then the results were compared. We also suggest examining the other kinds of reliability and validity of this test.
\end{abstract}

\section{* Corresponding Author:}

Mehdi Alizadeh Zarei, PhD

Address: Department of Occupational Therapy, Faculty of Rehabilitation, Iran University of Medical Sciences, Shahnazari St., Madar Sq., Mirdamad Blv., Tehran, Iran.

Tel: +98 (21) 22228051

E-Mail: mehdii.alizadeh@yahoo.com 


\title{
تهيه نسخه فارسى (ايرسشنامه سنجش رفتارى كاركرد اجرايى - نسخه ييش دبستانى) و بررسى

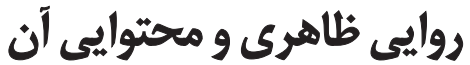

\author{
فروزان عبداللهىيور'، "مهدى علىزادزارعى'، ملاحت اكبرفهيمى'، سمانه كرمعلى|سماعيلى'
}

1- كروه كاردرمانى، دانشكده توانبخشى، دانشعاه علوم يزشكى ايران، تهران، ايران.

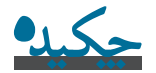

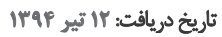

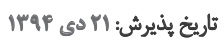

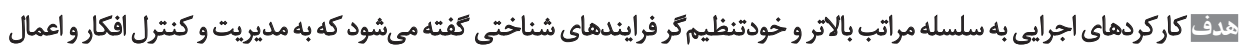

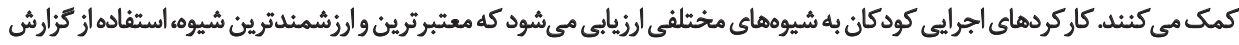

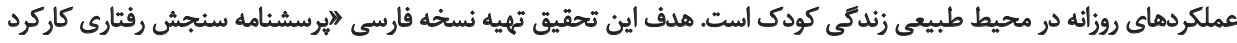

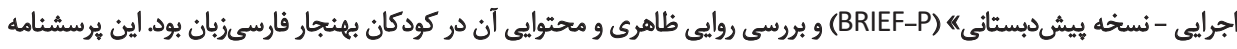

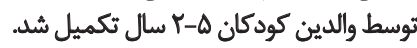

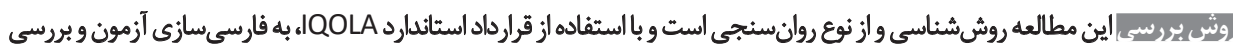

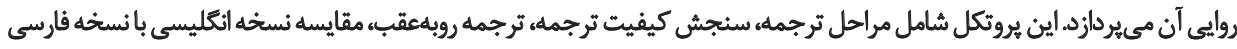

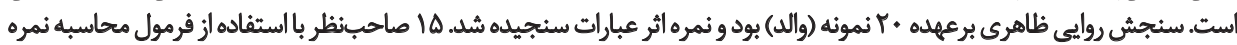

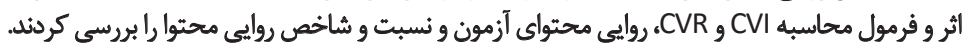

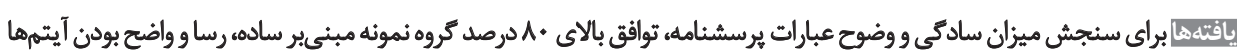

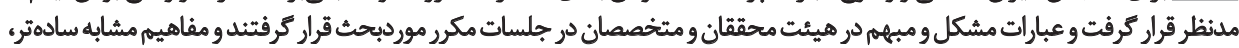

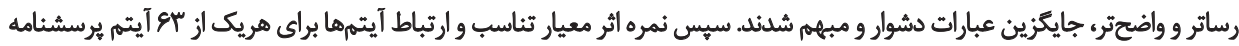

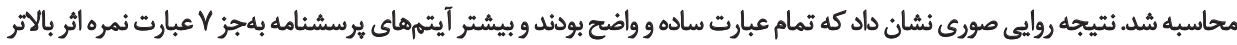

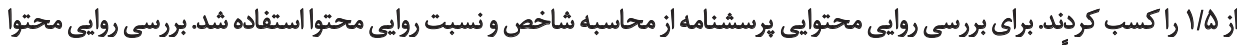

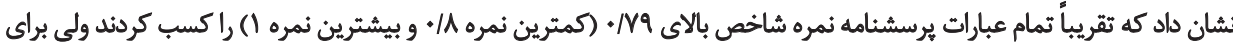

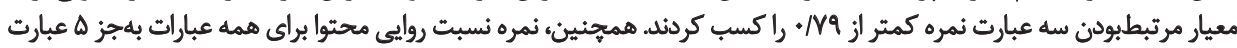

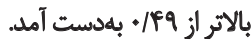

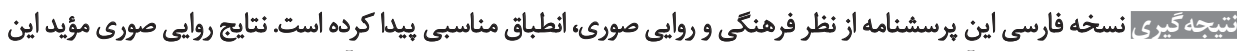

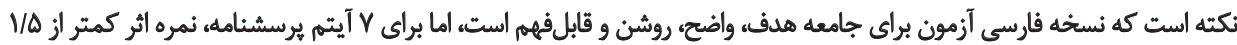

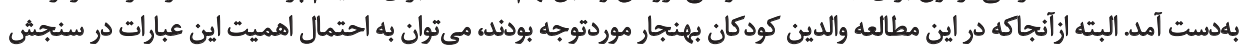

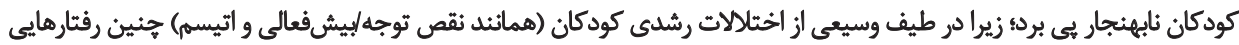

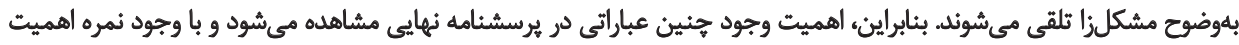

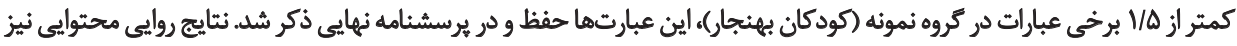

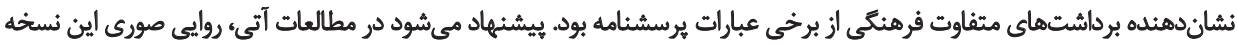

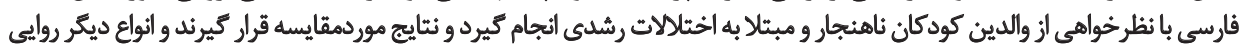

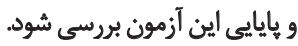

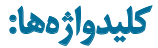

بيشدبستان، روايى، كاركرد اجرايى، كو
\end{abstract}


اجزاى خاص كاركردهاى اجرايى را مشخص نمي كنند؛

مقلمه

• •تايج بيشتر اين آزمونها ارتباط مشخصى با عملكرد واقعى زئي

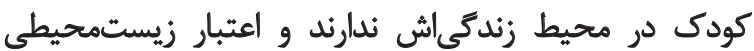

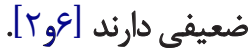

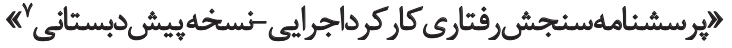

(BRIEF-P)

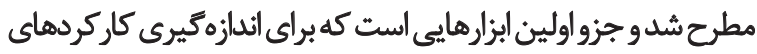

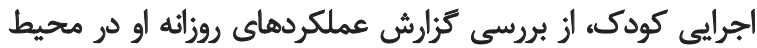

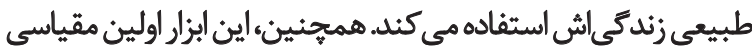

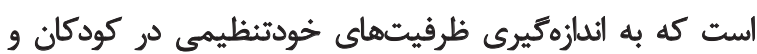

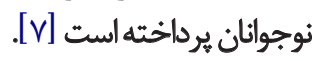

ر F نسخه مختلف از برسشنامه سنجش رفتارى كاركرد اجرايى

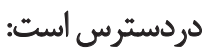

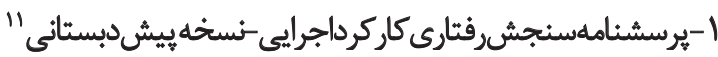

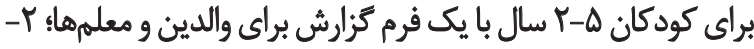

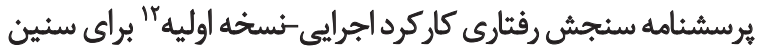
11

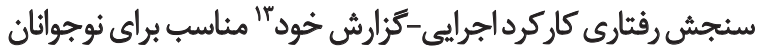

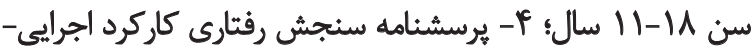

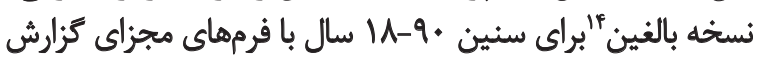

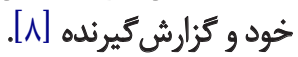

يرسشنامه سنجش رفتارى كاركرداجرايى -نسخه بيش دابستاني

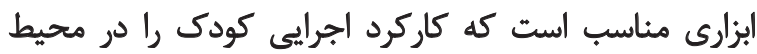

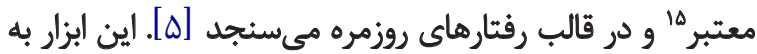

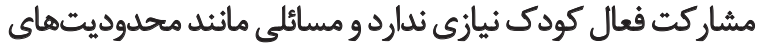

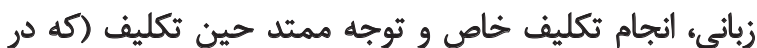

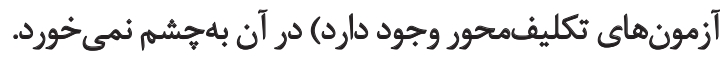
نسخه اوليه يرسشنامه سنجش رفتارى كاركرد اجرايى - كه به

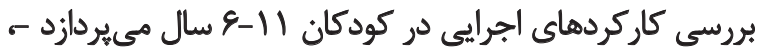

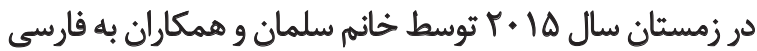

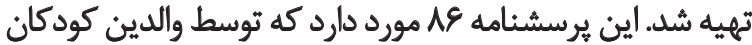
تكميل مى تردد. نتايج روايى صورى اين مطالعه نشارئ نشان داد كاد كه

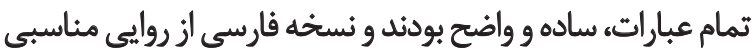

7. Behavior Rating Inventory of Executive Function

8. Espy

9. Isquith

10. Gioia

11. BRIEF-preschool

12. Original BRIEF

13. BRIEF-self report

14. BRIEF-adult version

15. Ecologically valid fashion

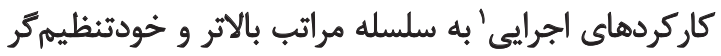

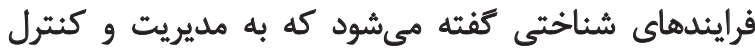

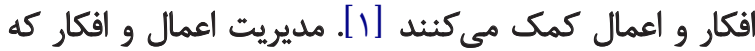

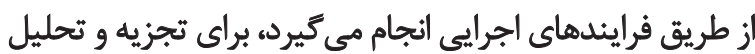

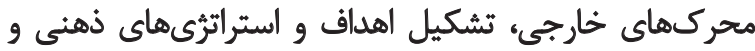

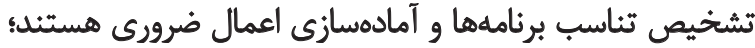

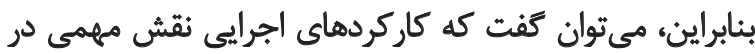

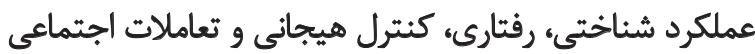

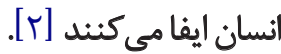

كاركردهاى اجراييى از جمله حياتىترين عملكردهاى شناختى

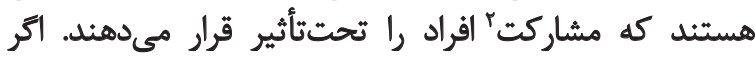

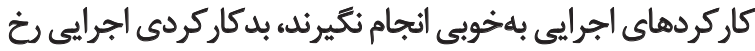

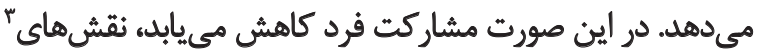

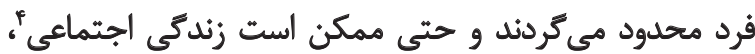

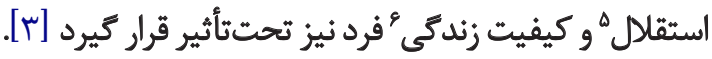
سير تكامل كاركردهاى اجرايى باطول دوره رشد عصبشناختى كانى

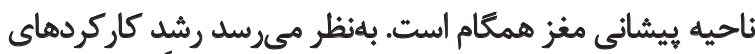

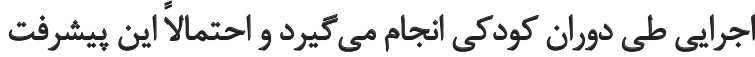

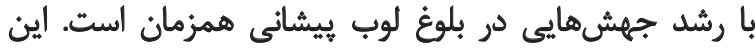

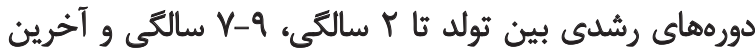

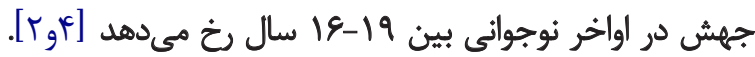

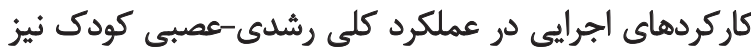

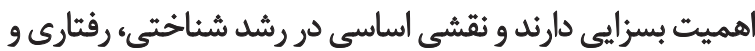

اجتماعي هيجاني كودى ايفا مي كنيند [هارند.

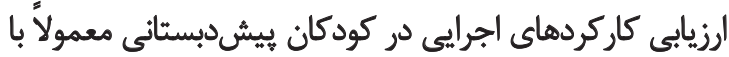

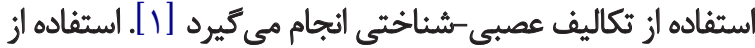

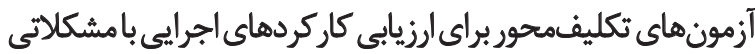

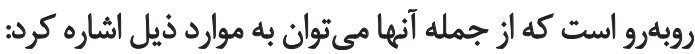

• اين ابزارها قابليت تكراريذيرى ندارند؛ زيرا براى رويارويى با باريا

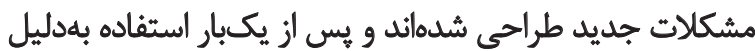

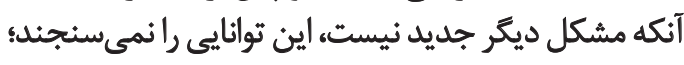
• اين تكاليف ناخالص هستند و ممكن است بهكاركيرى آنها فرايندهاى شناختى ديكر رانيز بهكار كيرد؛ • بيشتر اين آزمونها از نمرات خلاصه استفاده ميكنيند و

1. Executive function

2.Participation

3.Roles

4. Community living

5. Independence

6. Quality of life 


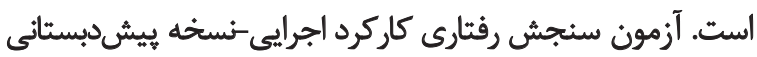

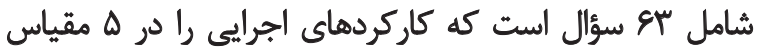

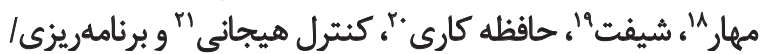

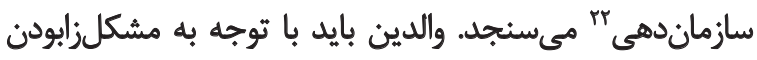

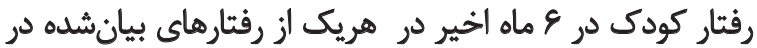

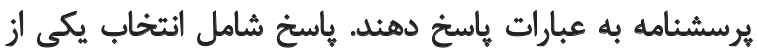

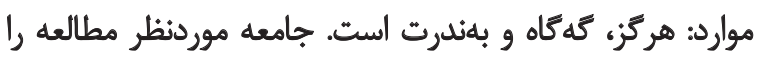

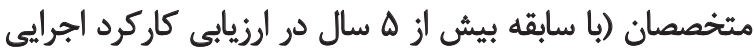

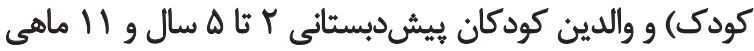

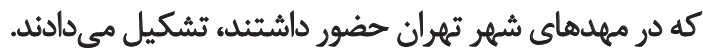
براي انجام اين مطالعه ابتدا يرسشنامه از كشور آمريكا و مؤسسه

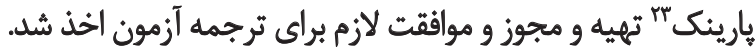

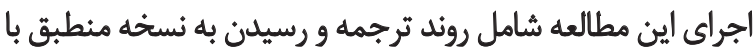

نسخه اصلى آزمون، روايى صورى و روايى محتوايى آزمون بودي

$$
\text { ترجمه و معادل سازي آزمون }
$$

ترجمه و معادلسازى آزمون با فرهنگ ايرانى براساس قرارداد

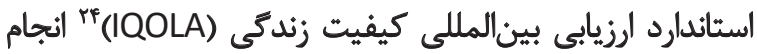

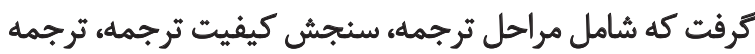

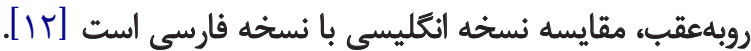

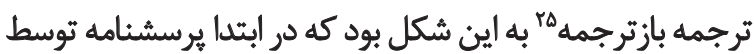

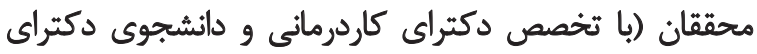

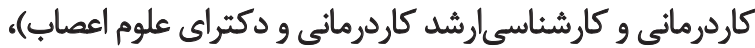

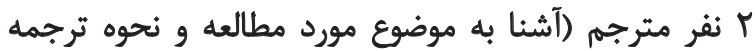

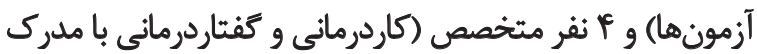

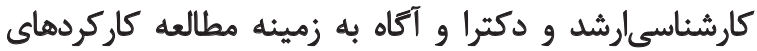
اجرايى كه در ارزيابى و درمان كودكان بيش از از هار سال سابقه داشتند) به فارسى ترجمه شر ارئ

ترجمه فارسى توسط محققان، Y مترجم و F أفر متخصص

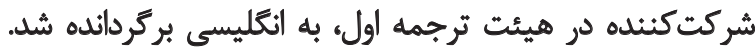

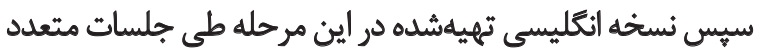

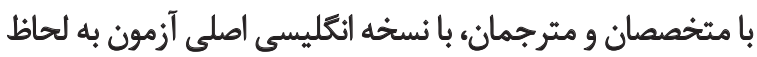

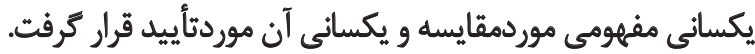

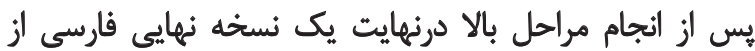

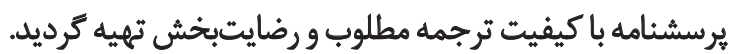

18. Inhibit

19. Shift

20. Working memory

21. Emptional control

22. Plan/Organize

23. Parinc

24. International Quality of Life Assessment

25. Translation-back translation
برخوردار است [9].

نسخههاي ديكر يرسشنامه سنجش رفتارى كاركرد اجرايى در

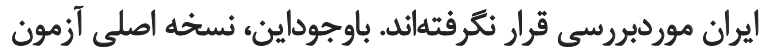

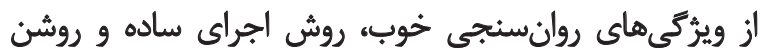

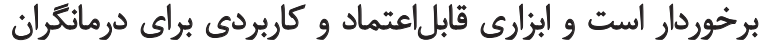

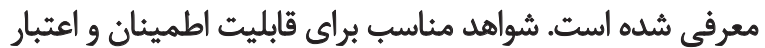

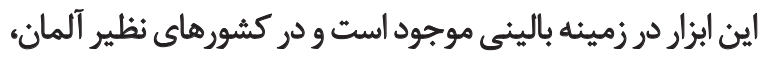

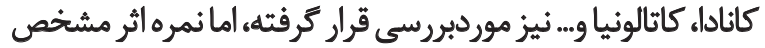

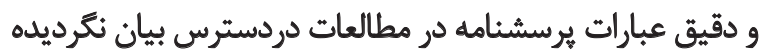

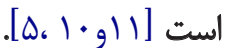

امروزهسنجش كاركردهاى اجرايى،بسيار موردتوجه متخصصان

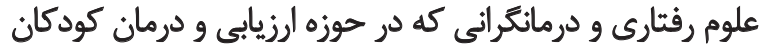

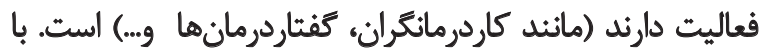

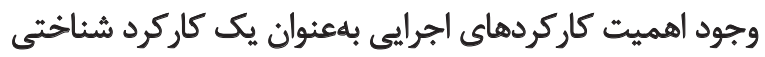

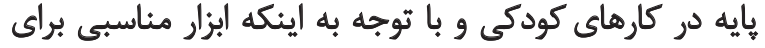

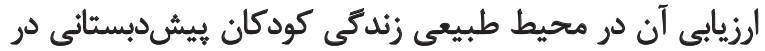

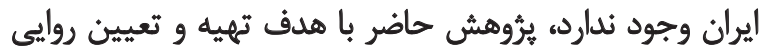

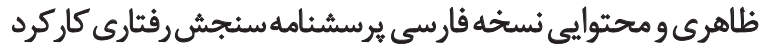

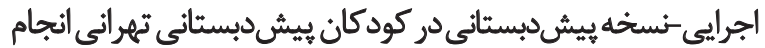

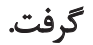

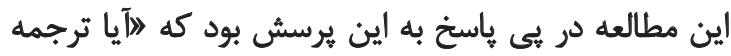

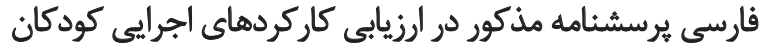

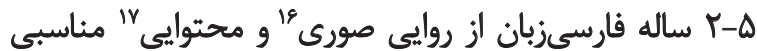

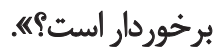

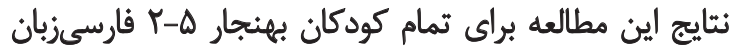

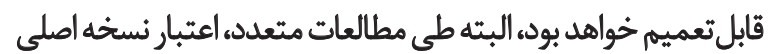

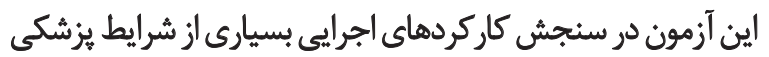

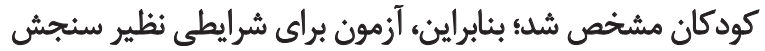

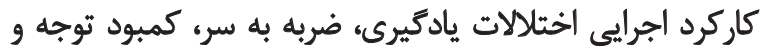

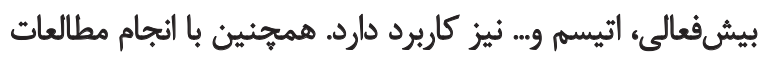

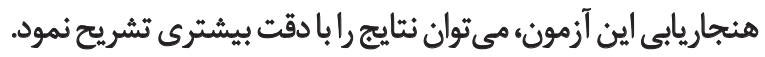

$$
\text { روش برورى ته }
$$

يثروهش حاضر، بُروهشى روششناسى بود و با هدف تعيين

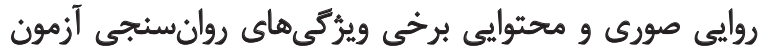

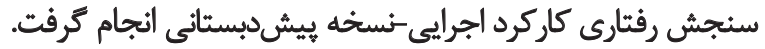

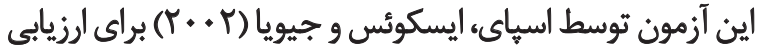

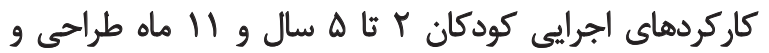

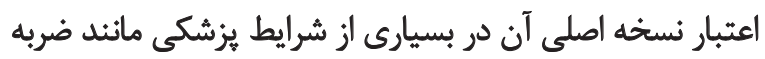

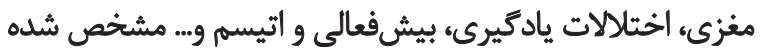

16. Face validity

17. Content validity 


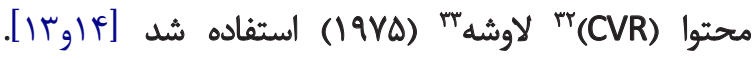

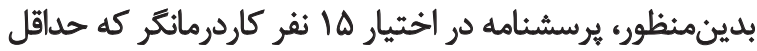

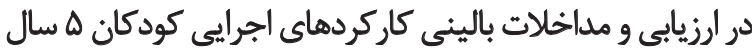

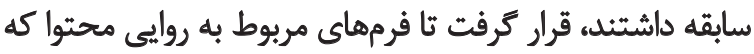

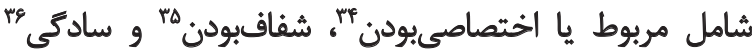

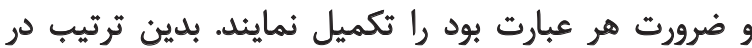

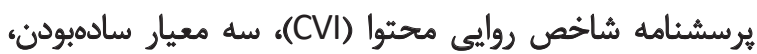

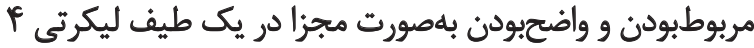

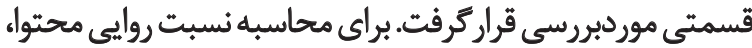

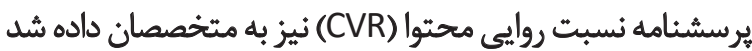
تا به موارد يرسشنامه از لحاظ ضرورى بودن نمبت نيز بهره دهند.

نمرات اين بخش نيز از طيف ليكرتى بيروى ميكى بردند كه

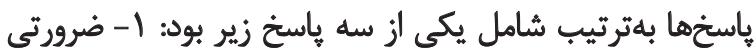

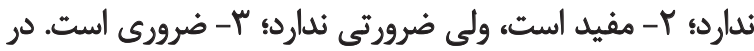

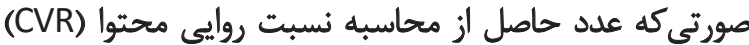

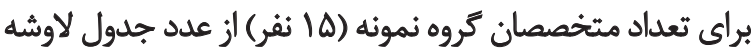

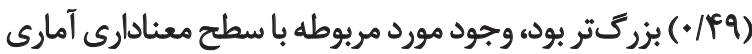

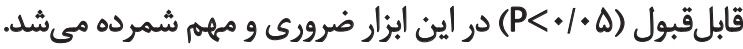

ياقتههها

براى سنجش ميزان سادتى و وضوح عبارات برسشنامه، ثوافق

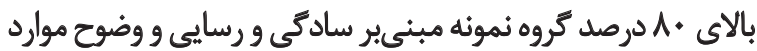

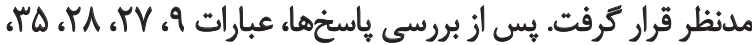

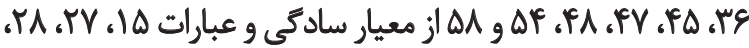

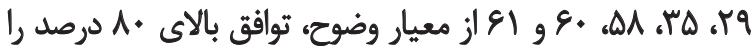

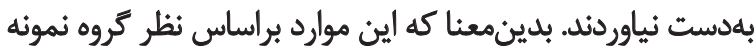

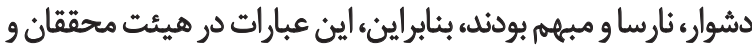

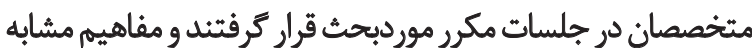

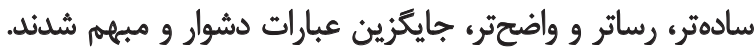

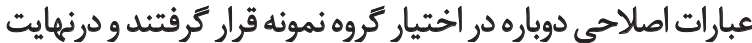

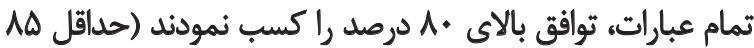

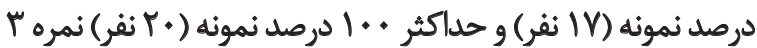
و F را به ساده و رسابونن عبارات اختصاص دادند).

نمره اثر معيار تثاسب و ارتباط موارد براى هريك از بهو مورد

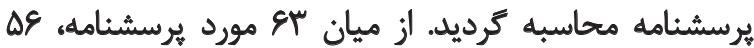

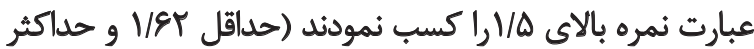

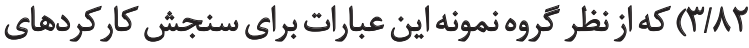

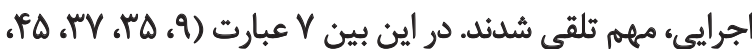

32. Content Validity Ratio (CVR)

33. Lawshe

34. Relevancy (Specificity)

35. Clarity

36. Simplicity
رواينى ظاهرى

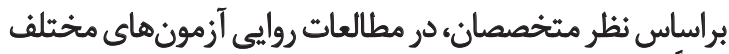

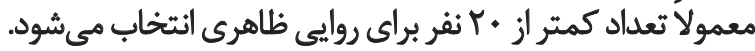

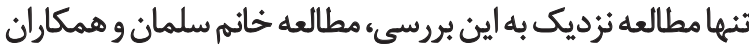

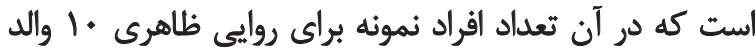

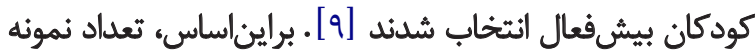

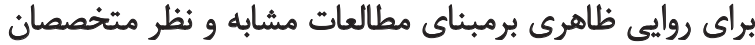

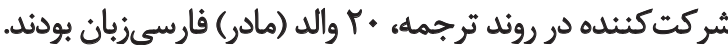

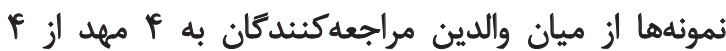

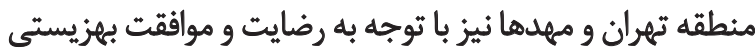

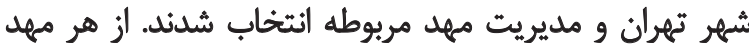

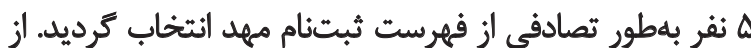

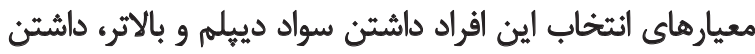

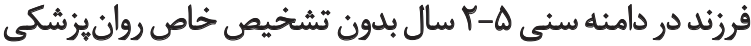

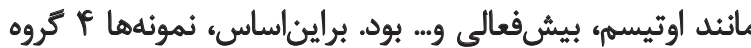

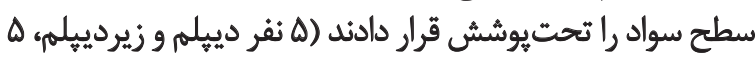
نفر فوقدييله، V نفر ليسانس، ب نفر فوق ليسانس و بالاتر). فرم روايى صورى يرسشنامه ترجماهشده به زبان فارسى در

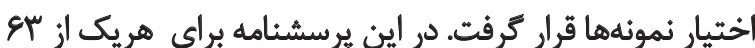

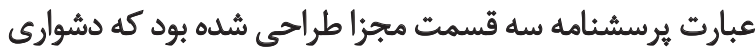

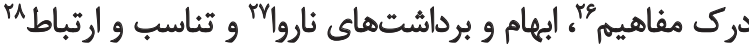

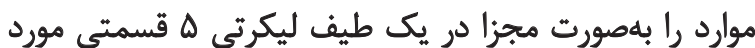

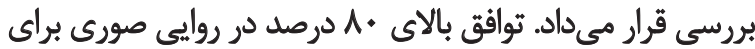

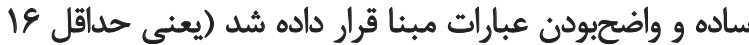

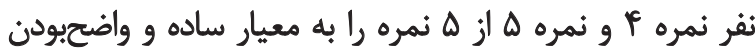

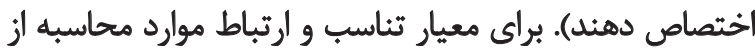

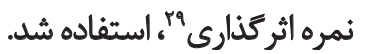
توافق بالاي •1 درصد و نمره اثر بالاي ه/ 1/ بدين معناست كه

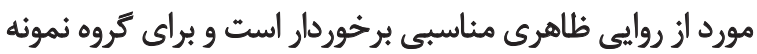

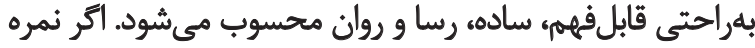

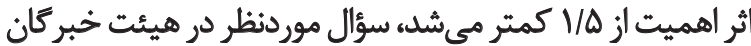

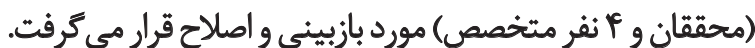

$$
\text { بررسى رواييى محتوايى }
$$

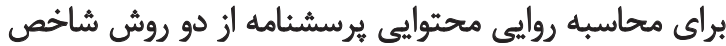

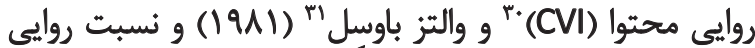

26. Difficulty

27. Ambiguous

28. Relevancy

29. Impact score

30. Content Validity Index (CVI)

31. Waltz Bausell 


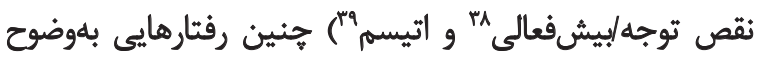

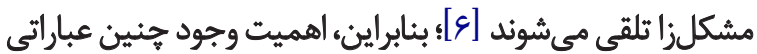

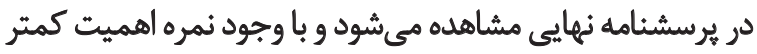

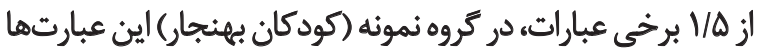

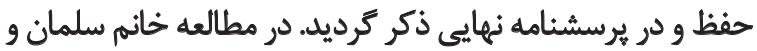

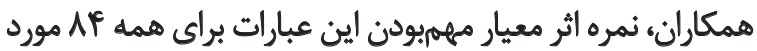

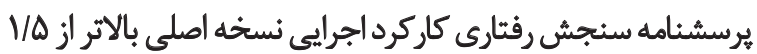

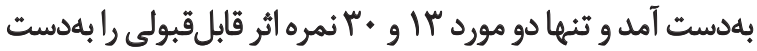

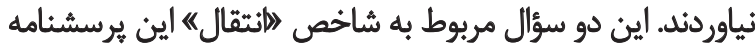

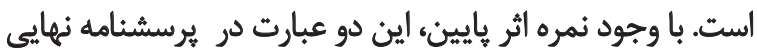

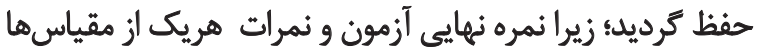

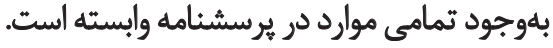

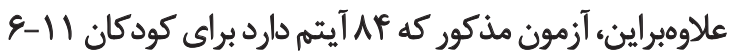

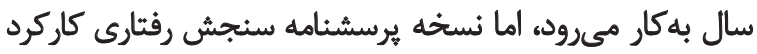

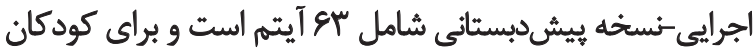

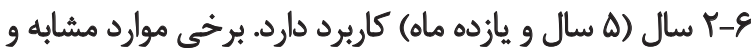

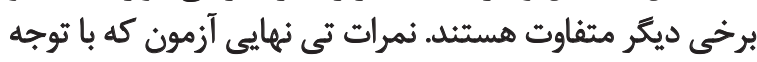

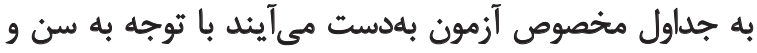

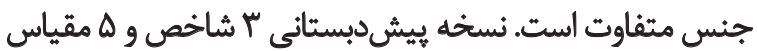

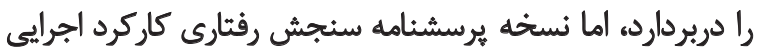
طراحى متفاوتى دارد.

آزمون سنجش رفتارى كاركرداجرايى براي سنجش كاركردهاي

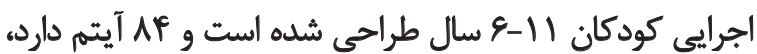

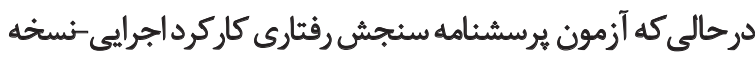

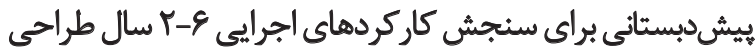

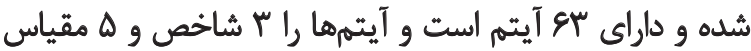

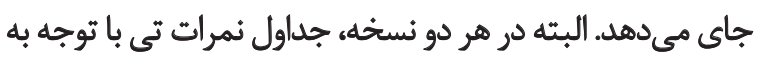

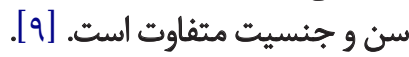
نتايج شاخص روايى محتوايى (نمرات CVI بالاتر از

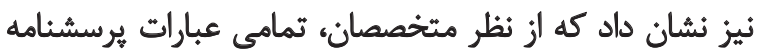

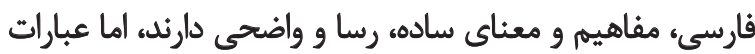

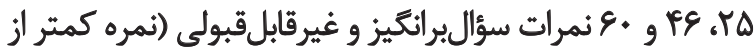

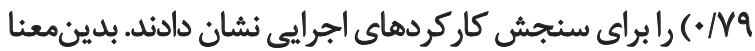

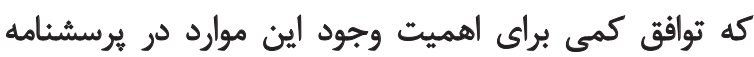

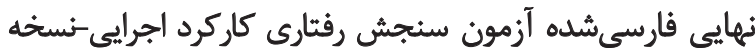

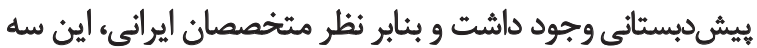
عبارت در سنجش كاركردهاي اجرايي كودكان ايرانى ازئن تناسب و كارايى مناسبى برخوردار نبودند كاركردي اجرائ.

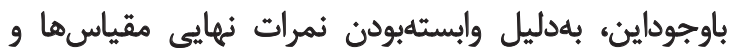

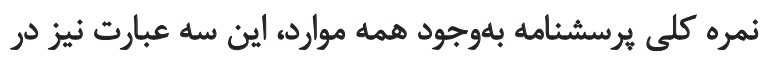

38. ADHD

39. Autism
كA FA

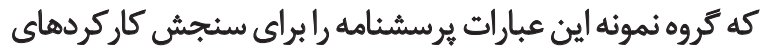
اجرائى كودكان بهنجار ايرائى مرهم ندائستند.

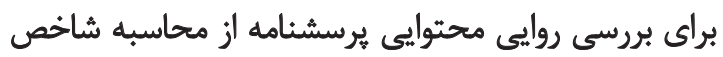

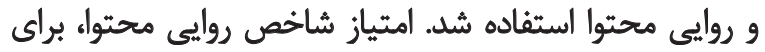

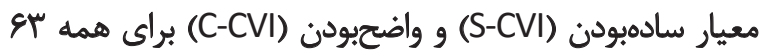

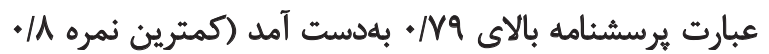

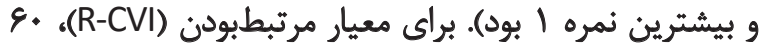

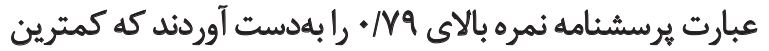

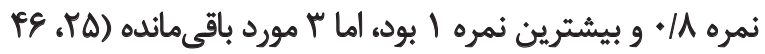

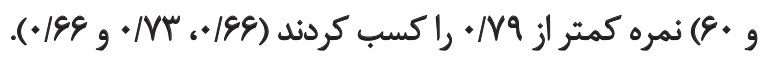

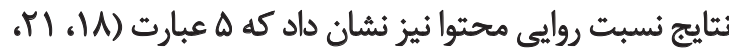

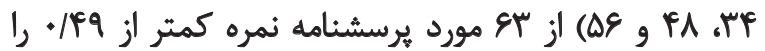

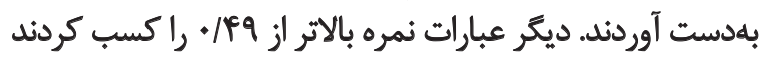

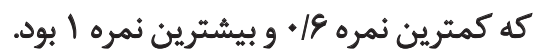

ب

در اين مطالعه، مراحل تر جمه براساس قرارداد استاندارد ارزيابي

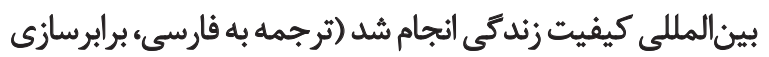

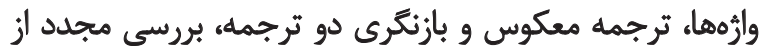

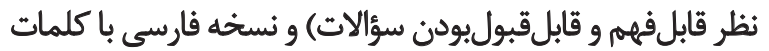

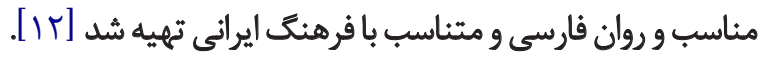
نتايج روايى ظاهرى نيز مؤيد اين نكته است كه نسخه فارسى

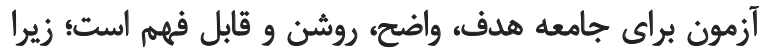

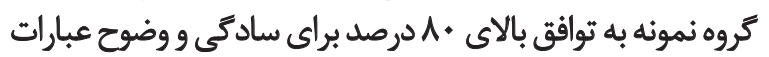

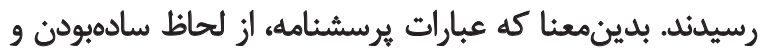

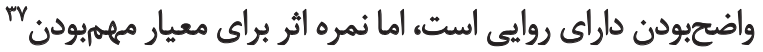

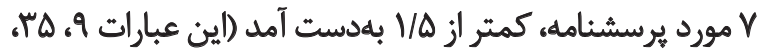
( ) البته اين نتيجه را مىتوان بهدلايل مختلفى نسبت داد. از براز

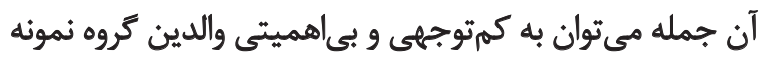

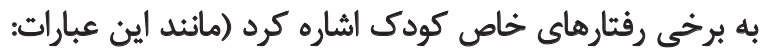

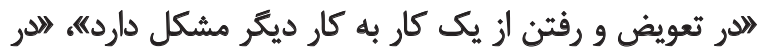

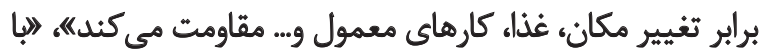

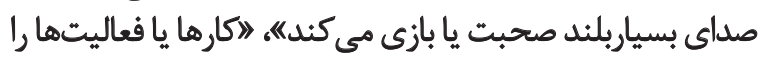

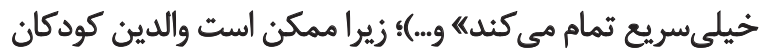

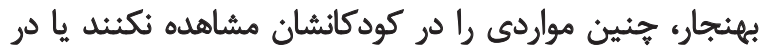

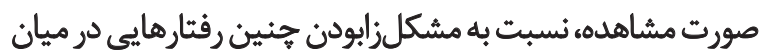

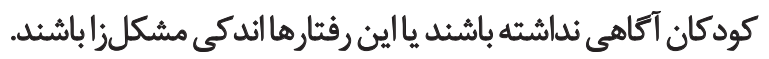
باوجوداين، در طيف وسيعى از اختلالات رشدى كودكان (هماند

37. Relevancy IS 
به اختلالات رشدى أنجام كيرد و نتايج مورد مقايسه قرار كيرند و انواع ديكر روايى و پايايى اين آزمون نيز بررسى شود.

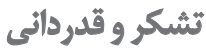

با تقدير و تشكر فراوان از اعضاى هيئت متخصصان سركار

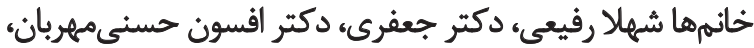

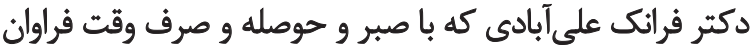
متعهدانه و دلسوزانه ما را در اين امر يارى رساندند.
نسخه فارسى برسشنامه سنجش رفتارى كاركرد اجرايى-سنسخه

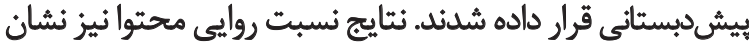

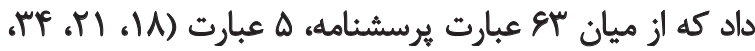

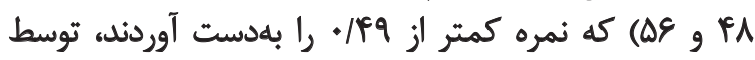

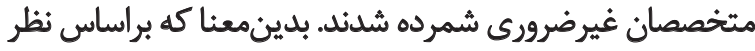

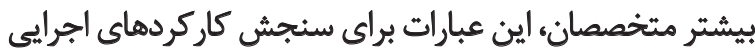

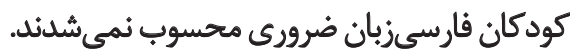

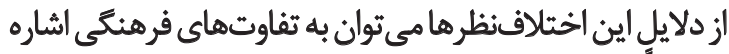

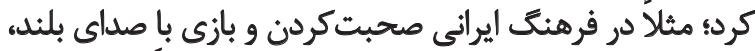

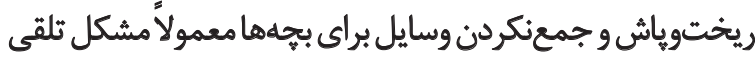

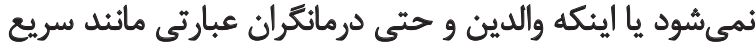

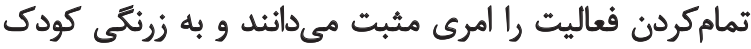

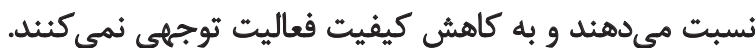

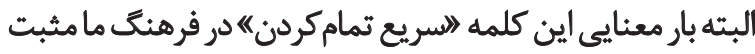

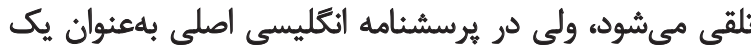
مشكل تلقى شده است.

در دو عبارت وارٔه انكليسى Silly بهكار فيته است كه متأسفانه

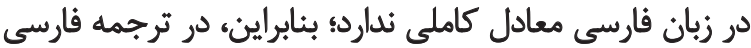

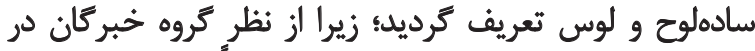

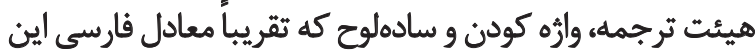

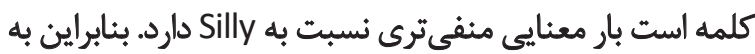

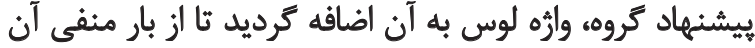

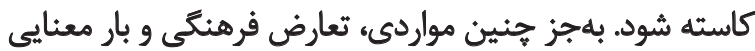
خاص ديكرى در ترجمه مشاهده نتخرديد.

نتيجهيكَ

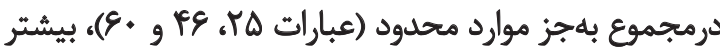

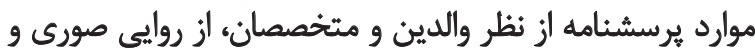

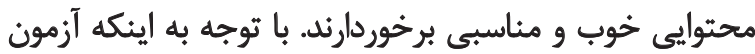

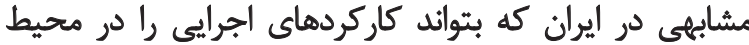

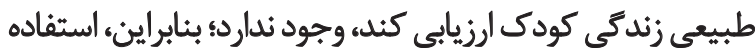

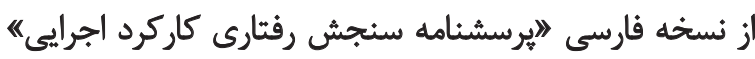

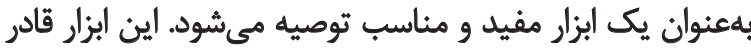

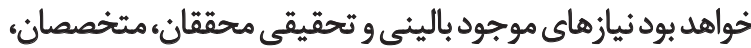

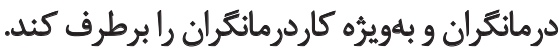

از مشكلات ومحدوديتهاي اين مطالعه مي توان به عدمدسترسي

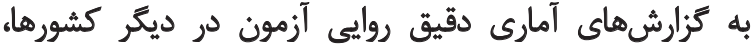

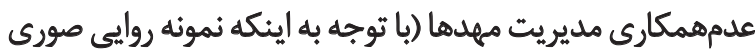

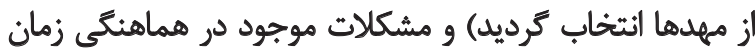
جلسات با متخصصان و مثر جمان جلسات ترجمه اشاره نمود. يُيشنهاد ميشود كه در مطالعات آتى روايى ظاهرى اين نسخه فارسى با نظرخواهى از والدين كودكان ناهنجار و مبت مبتلا 


\section{References}

[1] Carlson SM. Developmentally sensitive measures of executive function in preschool children. Developmental Neuropsychology. 2005; 28(2):595-616.

[2] Anderson P. Assessment and development of executive function (EF) during childhood. Child Neuropsychology. 2002; 8(2):71-82.

[3] Cramm HA, Missiuna CA, Lysaght RM, Parker KH. Executive functioning: A scoping review of the occupational therapy literature. Canadian Journal of Occupational Therapy. 2013; 80(3):40131.

[4] Anderson V. Assessing executive functions in children: Biological, psychological, and developmental considerations. Developmental Neurorehabilitation. 2001; 4(3):36-119.

[5] Isquith PK, Crawford JS, Espy KA, Gioia GA. Assessment of executive function in preschool-aged children. Mental Retardation and Developmental Disabilities Research Reviews. 2005; 11(3):209-15.

[6] Jurado MB. The elusive nature of executive functions: A review of our current understanding. Neuropsychology Review. 2007; 17(3):33-213.

[7] Gioia GA, Isquith PK, Guy SC, Kenworthy L. Test review behavior rating inventory of executive function. Child Neuropsychology. 2000; 6(3):235-8.

[8] Gioia GA, Espy KA, Isquith PK. BRIEF-P: Behavior Rating Inventory of Executive Function-Preschool Version (BRIEF-P). Odessa, FL: Psychological Assessment Resources; 2002.

[9] Salman MohammadThaqi N. [Study of face validity and reliability of Persian-version Behavior Rating Inventory of Executive Function (BRIEF) in ADHD Children-Persian (Persian)] [MSc. thesis]. Tehran: Iran University of Medical Science.

[10] Duku E, Vaillancourt T. Validation of the BRIEF-P in a sample of Canadian preschool children. Child Neuropsychology. 2014; 20(3):358-71.

[11] Bonillo A, Araujo Jiménez EA, Jane Ballabriga MC, Capdevila C, Riera R. Validation of Catalan Version of BRIEF-P. Child Neuropsychology. 2012; 18(4):347-55.

[12] Bullinger M, Alonso J, Apolone G, Leplège A, Sullivan M, Wood-Dauphinee S, et al. Translating health status questionnaires and evaluating their quality: The IQOLA project approach. Journal of Clinical Epidemiology. 1998; 51(11):913-23.

[13] Lawshe CH. A quantitative approach to content validity1. Personnel Psychology. 1975; 28(4):563-75.

[14] Waltz CF, Bausell BR. Nursing research: Design statistics and computer analysis. Philadelphia: Davis FA; 1981. 